\title{
Long-term behavior of lime-metakaolin pastes at ambient temperature and humid curing condition
}

\author{
A. Santos Silva ${ }^{a}$, A. Gameiro ${ }^{a}, J$. Grilo ${ }^{a}$, R. Veiga ${ }^{a}$, A. Velosa ${ }^{b}$ \\ a National Laboratory for Civil Engineering, Av. do Brasil, 101, Lisbon, Portugal \\ ${ }^{b}$ Department of Civil Engineering, Geobiotec, University of Aveiro, Aveiro, Portugal
}

\begin{abstract}
This paper presents the reaction behavior of lime and metakaolin (MK) pastes submitted to long term aging at ambient temperature and relative humidity of $95 \pm 5 \%$. The results presented are the basis for an extensive research pointing towards the formulation of lime based mortars for conservation of historic buildings, namely in humid environments.

MK, when mixed with calcium hydroxide, in the presence of water, originates a set of major hydrated compounds, specifically, stratlingite, monocarboaluminate and calcium aluminate hydrate. The type of hydrated compounds formed is dependent on the lime/MK ratio, being some of them unstable over time. This instability can compromise the mechanical properties of lime-MK mortars. From this work different reaction kinetics with aging were perceived, being the best results in terms of the pozzolanic reaction obtained with $50 \%$ MK content. Pastes with less than $25 \%$ of MK also present reliable stability.
\end{abstract}

Keywords:

Air lime-metakaolin paste; XRD; TG-DTA; Hydration products; Pozzolanic reactions 